Available online at www.eccomasproceedia.org

Eccomas Proceedia COMPDYN (2021) 4452-4466

ECCOMAS Proceedia
COMPDYN 2021

$8^{\text {th }}$ ECCOMAS Thematic Conference on Computational Methods in Structural Dynamics and Earthquake Engineering

M. Papadrakakis, M. Fragiadakis (eds.)

\title{
SEISMIC PERFORMANCE OF BRIDGES ISOLATED WITH FPS
}

\author{
P. Castaldo', and G. Amendola ${ }^{2}$ \\ ${ }^{1}$ Department of Structural, Geotechnical and Building Engineering (DISEG), Politecnico di Torino, \\ Turin, Italy \\ e-mail: paolo.castaldo@polito.it ; pcastaldo@unisa.it \\ ${ }^{2}$ Department of Structural, Geotechnical and Building Engineering (DISEG), Politecnico di Torino, \\ Turin, Italy \\ e-mail: guglielmo.amendola@polito.it
}

\begin{abstract}
The scope of the present study is focused on the evaluation of the seismic response of bridges isolated by single concave sliding pendulum isolators (FPS) for the different structural properties when the presence of the rigid abutment is considered or neglected (i.e., isolated viaducts). In this way, they have been defined two specific multi-degree-of-freedom (mdof) models to simulate the elastic behavior of the reinforced concrete pier in combination to the infinitely rigid presence of the deck and to the presence of the rigid abutment if considered. Both the numerical models also account for the non-linear velocity-dependent behavior of the FPS bearings. Considering the aleatory uncertainty in the seismic input by means of several natural records with different characteristics, a parametric analysis is developed for several structural properties. The relevant results expressed as the statistics in non-dimensional form with respect to the seismic intensity have permitted to study the differences between the two numerical models in relation to the effectiveness of the seismic isolation.
\end{abstract}

Keywords: Seismic isolation, Bridge, Friction pendulum isolators, Performance-based engineering, Seismic reliability. 


\section{INTRODUCTION}

Seismically isolated bridges permit to obtain a substantial reduction of the deck acceleration and, as consequence, of the forces transmitted to the pier in comparison to non-isolated bridges as widely demonstrated in many studies focusing with both elastomeric (LRB) and frictional (FPS) isolators [2]-[8]. This topic is in line with the issue of the infrastructure safety [9]-[10]. Tongaonkar and Jangid [11] evaluated the effects of soil-structure interaction on the peak responses of a three-span continuous deck bridge isolated by the elastomeric bearings particularly, showing their influence to assess the bearing displacements at abutment locations. Contextually, friction pendulum system (FPS) devices have been widely used for their capability to provide an isolation period mass independent and to assure high dissipation and recentering in addition to their longevity and durability properties [12]-[14]. Several experimental and numerical researches have explored the behavior of the FPS devices [15][23]. The seismic response of isolated multi-span continuous deck bridges is investigated in [24] confirming the effectiveness of simplified models in relation to the flexibility of the deck and of the piers. In [25]-[26], it was carried out a large parametric analysis demonstrating the influence of the design parameters on the response of a three-dimensional multi-span continuous steel girder bridge model seismically isolated by the FPS isolators. Moreover, other works have been more oriented to develop design approaches for the isolators. In this context, the seismic reliability-based design (SRBD) approach has been proposed and widely discussed in [27]-[34] as a new methodology mainly aim to provide design solutions for seismic devices taking into account the main uncertainties relevant to the problem itself.

The main goal of this work consists in evaluating the influence of the pier-abutment-deck interaction on the seismic response of bridges isolated by single concave sliding pendulum isolators (FPS) mainly comparing the results with those coming from the seismic response of isolated bridges without considering the presence of the rigid reinforced concrete (RC) abutment (i.e., isolated viaducts). With this aim, two different multi-degree-of-freedom (mdof) models representative, respectively, of a single-column bent viaduct [22] and a multi-span continuous deck bridge [7],[13] are defined. Specifically, a six-degree-of-freedom model is used to represent the dynamic behaviour of both the isolated bridge systems. In fact, in both the mdof models, five vibrational modes are considered to describe the elastic behavior of the $\mathrm{RC}$ pier and an additional degree of freedom represents the response of the infinitely rigid $\mathrm{RC}$ deck isolated by the FPS devices. If considered, the presence of the RC abutment is assumed rigid and so no degree of freedom is related to that. The FPS isolator behavior is described through a widespread velocity-dependent model. In order to obtain a system response independent from the specific seismic source, a non-dimensional formulation of the motion equations proposed in [20] and herein extended and, in addition, a parametric analysis considering several structural properties is performed with the aim to investigate the differences between the two mdof models in relation to the relevant response parameters. The uncertainty in the seismic input is taken into account by means of a set of natural records with different characteristics. Finally, the optimum values of the sliding friction coefficient able to minimize the pier displacements relative to the ground as a function of the structural properties and of the seismic input intensity considering or neglecting the rigid presence of the abutment (i.e., single-column bent viaduct and multi-span continuous deck bridge) have been derived. 


\section{NON-DIMENSIONAL MOTION EQUATIONS}

The motion equations, in terms of drifts between the different degrees of freedom, governing the seismic response when the isolated system refers to a multi-span continuous deck bridge (e.g., three-span continuous deck bridge) [7],[13], and the presence of the rigid RC abutment is considered (Figure 1(b)), subjected to the seismic input along the longitudinal direction, $\ddot{u}_{g}(t)$, are:

$$
\begin{aligned}
& m_{d} \ddot{u}_{d}(t)+m_{d} \ddot{u}_{p 5}(t)+m_{d} \ddot{u}_{p 4}(t)+m_{d} \ddot{u}_{p 3}(t)+m_{d} \ddot{u}_{p 2}(t)+m_{d} \ddot{u}_{p 1}(t)+c_{d} \dot{u}_{d}(t)+F_{p}(t)+F_{a}(t)=-m_{d} \ddot{u}_{g}(t) \\
& m_{p 5} \ddot{u}_{p 5}(t)+m_{p 5} \ddot{u}_{p 4}(t)+m_{p 5} \ddot{u}_{p 3}(t)+m_{p 5} \ddot{u}_{p 2}(t)+m_{p 5} \ddot{u}_{p 1}(t)-c_{d} \dot{u}_{d}(t)+c_{p 5} \dot{u}_{p 5}(t)+k_{p 5} u_{p 5}(t)-F_{p}(t)=-m_{p 5} \ddot{u}_{g}(t) \\
& m_{p 4} \ddot{u}_{p 4}(t)+m_{p 4} \ddot{u}_{p 3}(t)+m_{p 4} \ddot{u}_{p 2}(t)+m_{p 4} \ddot{u}_{p 1}(t)-c_{p 5} \dot{u}_{p 5}(t)-k_{p 5} u_{p 5}(t)+c_{p 4} \dot{u}_{p 4}(t)+k_{p 4} u_{p 4}(t)=-m_{p 4} \ddot{u}_{g}(t) \\
& m_{p 3} \ddot{u}_{p 3}(t)+m_{p 3} \ddot{u}_{p 2}(t)+m_{p 3} \ddot{u}_{p 1}(t)-c_{p 4} \dot{u}_{p 4}(t)-k_{p 4} u_{p 4}(t)+c_{p 3} \dot{u}_{p 3}(t)+k_{p 3} u_{p 3}(t)=-m_{p 3} \ddot{u}_{g}(t) \\
& m_{p 2} \ddot{u}_{p 2}(t)+m_{p 2} \ddot{u}_{p 1}(t)-c_{p 3} \dot{u}_{p 3}(t)-k_{p 3} u_{p 3}(t)+c_{p 2} \dot{u}_{p 2}(t)+k_{p 2} u_{p 2}(t)=-m_{p 2} \ddot{u}_{g}(t) \\
& m_{p 1} \ddot{u}_{p 1}(t)-c_{p 2} \dot{u}_{p 2}(t)-k_{p 2} u_{p 2}(t)+c_{p 1} \dot{u}_{p 1}(t)+k_{p 1} u_{p 1}(t)=-m_{p 1} \ddot{u}_{g}(t)
\end{aligned}
$$

where $u_{d}$ denotes the horizontal displacement of the deck relative to pier, $u_{p 1}, u_{p 2}, u_{p 3}, u_{p 4}, u_{p 5}$ are the pier displacements relative between two consecutive dof, $m_{d}, m_{p 1}, m_{p 2}, m_{p 3}, m_{p 4}, m_{p 5}$ respectively the mass of the deck and of each dof of the pier, $k_{p 1} k_{p 2}, k_{p 3}, k_{p 4}, k_{p 5}$ and $c_{p 1,} c_{p 2}, c_{p 3}, c_{p 4,} c_{p 5}$ respectively the stiffness and inherent viscous damping coefficient of each dof of the pier, $c_{d}$ the bearing viscous damping factor, $t$ the time instant, the dot differentiation over time.

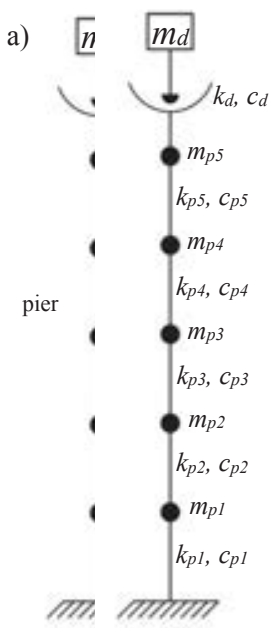

b)
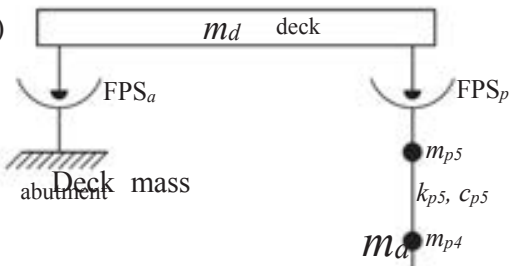

FPS isolator
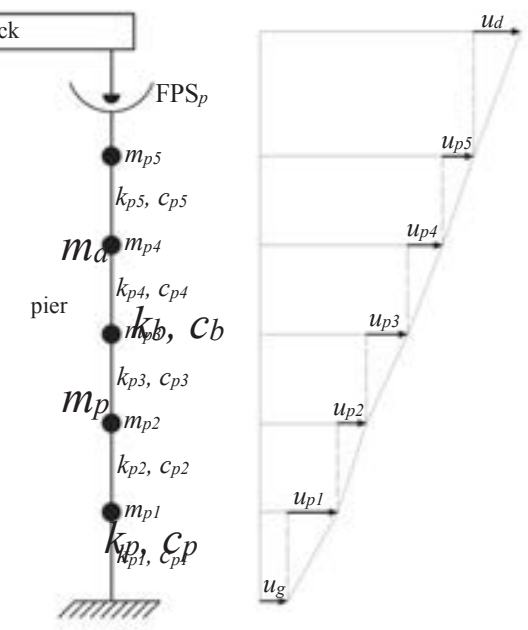

c) FP bearings

Base mass

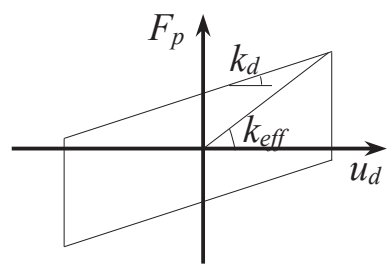

Figure 1: 6dof model of a bridge isolated by FPS bearings without pier-abutment-deck interaction (i.e., viaduct) (a); 6dof model of a bridge isolated by FPS bearings considering pier-abutment-deck interaction (b); FPS response (c).

The forces related to both the isolator device placed at the pier level $F_{p}(t)$ and at the abutment level $F_{a}(t)$ are the following:

$$
F_{p}(t)=\frac{m_{d} g}{2}\left[\frac{1}{R_{p}} u_{d}(t)+\mu_{p}\left(\dot{u}_{d}\right) \operatorname{sgn}\left(\dot{u}_{d}\right)\right]
$$




$$
F_{a}(t)=\frac{m_{d} g}{2}\left[\frac{1}{R_{a}}\left(u_{d}(t)+\sum_{i=1}^{5} u_{p i}\right)+\mu_{a}\left(\dot{u}_{d}(t)+\sum_{i=1}^{5} \dot{u}_{p i}\right) \operatorname{sgn}\left(\dot{u}_{d}(t)+\sum_{i=1}^{5} \dot{u}_{p i}\right)\right\rfloor
$$

where $k_{d}=W / R=m_{d} g / R, g$ is the gravity constant, $R$ is the radius of curvature of the FPS device, $\mu\left(\dot{u}_{d}(t)\right)$ the sliding friction coefficient, which depends on the bearing slip horizontal velocity $\dot{u}_{d}(t)$ [31], and $\operatorname{sgn}(\cdot)$ denotes the sign function. As reported in [14], the fundamental vibration period of an isolated bridge, $T_{d}=2 \pi \sqrt{R / g}$, corresponding to the pendulum behaviour component, depends only on the radius of curvature $R$. According to [16]-[19], the sliding friction coefficient of teflon-steel interfaces can be expressed by the following equation:

$$
\mu\left(\dot{u}_{d}\right)=\mu_{\max }-\left(\mu_{\max }-\mu_{\min }\right) \cdot \exp \left(-\alpha\left|\dot{u}_{d}\right|\right)
$$

where $\mu_{\max }$ and $\mu_{\min }$ represent, respectively, the maximum value of sliding friction coefficient attained at large velocities and the value at zero velocity. In this study, it is considered that $\mu_{\max }=3 \mu_{\min }$ with the exponent $\alpha$ equal to 30 [20].

What is worth underlying is that, differently to the reaction force of the seismic device on the pier, the reaction force as well as the friction coefficient related to the abutment isolator depend on both the horizontal velocity and displacement [31] of the deck with respect to the ground.

By dividing Eq. (1) by the mass deck $m_{d}$, the following equation system is obtained:

$$
\begin{aligned}
& \ddot{u}_{d}(t)+\ddot{u}_{p 5}(t)+\ddot{u}_{p 4}(t)+\ddot{u}_{p 3}(t)+\ddot{u}_{p 2}(t)+\ddot{u}_{p 1}(t)+2 \xi_{d} \omega_{d} \dot{u}_{d}(t)+\frac{g}{2}\left[\frac{1}{R_{p}} u_{d}(t)+\mu_{p}\left(\dot{u}_{d}\right) \operatorname{sgn}\left(\dot{u}_{d}\right)\right]+ \\
& +\frac{g}{2}\left[\frac{1}{R_{a}}\left(u_{d}(t)+\sum_{i=1}^{5} u_{p i}\right)+\mu_{a}\left(\dot{u}_{d}(t)+\sum_{i=1}^{5} \dot{u}_{p i}\right) \operatorname{sgn}\left(\dot{u}_{d}(t)+\sum_{i=1}^{5} \dot{u}_{p i}\right)\right]=-\ddot{u}_{g}(t) \\
& \lambda_{p 5}\left[\ddot{u}_{p 5}(t)+\ddot{u}_{p 4}(t)+\ddot{u}_{p 3}(t)+\ddot{u}_{p 2}(t)+\ddot{u}_{p 1}(t)\right]-2 \xi_{d} \omega_{d} \dot{u}_{d}(t)+2 \xi_{p 5} \omega_{p 5} \lambda_{p 5} \dot{u}_{p 5}(t)+\lambda_{p 5} \omega_{p 5}^{2} u_{p 5}(t)+ \\
& -\frac{g}{2}\left[\frac{1}{R_{p}} u_{d}(t)+\mu_{p}\left(\dot{u}_{d}\right) \operatorname{sgn}\left(\dot{u}_{d}\right)\right]=-\lambda_{p 5} \ddot{u}_{g}(t) \\
& \lambda_{p 4}\left[\ddot{u}_{p 4}(t)+\ddot{u}_{p 3}(t)+\ddot{u}_{p 2}(t)+\ddot{u}_{p 1}(t)\right]-2 \xi_{p 5} \omega_{p 5} \lambda_{p 5} \dot{u}_{p 5}(t)-\lambda_{p 5} \omega_{p 5}^{2} u_{p 5}(t)+2 \xi_{p 4} \omega_{p 4} \lambda_{p 4} \dot{u}_{p 4}(t)+ \\
& +\lambda_{p 4} \omega_{p 4}^{2} u_{p 4}(t)=-\lambda_{p 4} \ddot{u}_{g}(t) \\
& \lambda_{p 3}\left[\ddot{u}_{p 3}(t)+\ddot{u}_{p 2}(t)+\ddot{u}_{p 1}(t)\right]-2 \xi_{p 4} \omega_{p 4} \lambda_{p 4} \dot{u}_{p 4}(t)-\lambda_{p 4} \omega_{p 4}^{2} u_{p 4}(t)+2 \xi_{p 3} \omega_{p 3} \lambda_{p 3} \dot{u}_{p 3}(t)+\lambda_{p 3} \omega_{p 3}^{2} u_{p 3}(t)=-\lambda_{p 3} \ddot{u}_{g}(t) \\
& \lambda_{p 2}\left[\ddot{u}_{p 2}(t)+\ddot{u}_{p 1}(t)\right]-2 \xi_{p 3} \omega_{p 3} \lambda_{p 3} \dot{u}_{p 3}(t)-\lambda_{p 3} \omega_{p 3}^{2} u_{p 3}(t)+2 \xi_{p 2} \omega_{p 2} \lambda_{p 2} \dot{u}_{p 2}(t)+\lambda_{p 2} \omega_{p 2}^{2} u_{p 2}(t)=-\lambda_{p 2} \ddot{u}_{g}(t) \\
& \lambda_{p 1} \ddot{u}_{p 1}(t)-2 \xi_{p 2} \omega_{p 2} \lambda_{p 2} \dot{u}_{p 2}(t)-\lambda_{p 2} \omega_{p 2}^{2} u_{p 2}(t)+2 \xi_{p 1} \omega_{p 1} \lambda_{p 1} \dot{u}_{p 1}(t)+\lambda_{p 1} \omega_{p 1}^{2} u_{p 1}(t)=-\lambda_{p 1} \ddot{u}_{g}(t)
\end{aligned}
$$

and the following ratios are introduced:

$$
\omega_{d}=\sqrt{\frac{k_{d}}{m_{d}}}, \omega_{p i}=\sqrt{\frac{k_{p i}}{m_{p i}}}, \xi_{d}=\frac{c_{d}}{2 m_{d} \omega_{d}}, \xi_{p i}=\frac{c_{p i}}{2 m_{p i} \omega_{p i}}, \lambda_{p i}=\frac{m_{p i}}{m_{d}} \quad \text { with } i=1, \ldots, 5
$$

The first two terms denote, respectively, the circular frequency of vibration of the isolated deck and of the $i$-th lumped mass of the pier; $\xi_{d}$ is the damping factor of the isolated deck, 
$\xi_{p i}$ is the damping factor corresponding to the $i$-th dof in which the pier has been discretized. The last term represents the $i$-th mass ratio between the $i$-th lumped mass of the pier and the deck mass.

With the aim to extend the non-dimensionalization approach proposed by [20]-[21], let us introduce the time scale $\tau=t \omega_{d}$, in which $\omega_{d}=\sqrt{k_{d} / m_{d}}$ is the fundamental circular frequency of the isolated system with infinitely rigid superstructure, and the seismic intensity scale $a_{0}$, so that $\ddot{u}_{g}(t)=a_{0} \ell(\tau)$, where $\ell(\tau)$ is a non-dimensional function of time describing the seismic input time-history, the following non-dimensional equations can be obtained:

$$
\begin{aligned}
& \ddot{\psi}_{d}(\tau)+\ddot{\psi}_{p 5}(\tau)+\ddot{\psi}_{p 4}(\tau)+\ddot{\psi}_{p 3}(\tau)+\ddot{\psi}_{p 2}(\tau)+\ddot{\psi}_{p 1}(\tau)+2 \xi_{d} \dot{\psi}_{d}(\tau)+\left[\frac{1}{2} \psi_{d}(\tau)+\frac{\mu_{p}\left(\dot{\psi}_{d}\right) g}{2 a_{0}} \operatorname{sgn}\left(\dot{\psi}_{d}\right)\right]+ \\
& +\left[\frac{1}{2}\left(\psi_{d}(\tau)+\sum_{i=1}^{5} \psi_{p i}(\tau)\right)+\frac{g}{2 a_{0}}\left(\mu_{a}\left(\dot{\psi}_{d}(\tau)+\sum_{i=1}^{5} \dot{\psi}_{p i}(\tau)\right)\right)\left(\operatorname{sgn}\left(\dot{\psi}_{d}(\tau)+\sum_{i=1}^{5} \dot{\psi}_{p i}(\tau)\right)\right)\right]=-\ell(\tau) \\
& \lambda_{p 5}\left[\ddot{\psi}_{p 5}(\tau)+\ddot{\psi}_{p 4}(\tau)+\ddot{\psi}_{p 3}(\tau)+\ddot{\psi}_{p 2}(\tau)+\ddot{\psi}_{p 1}(\tau)\right]-2 \xi_{d} \dot{\psi}_{d}(\tau)+2 \xi_{p 5} \frac{\omega_{p 5}}{\omega_{d}} \lambda_{p 5} \dot{\psi}_{p 5}(\tau)+ \\
& +\lambda_{p 5} \frac{\omega_{p 5}^{2}}{\omega_{d}^{2}} \psi_{p 5}(\tau)-\left[\frac{1}{2} \psi_{d}(\tau)+\frac{\mu_{p}\left(\dot{\psi}_{d}\right) g}{2 a_{0}} \operatorname{sgn}\left(\dot{\psi}_{d}\right)\right]=-\lambda_{p 5} \ell(\tau) \\
& \lambda_{p 4}\left[\ddot{\psi}_{p 4}(\tau)+\ddot{\psi}_{p 3}(\tau)+\ddot{\psi}_{p 2}(\tau)+\ddot{\psi}_{p 1}(\tau)\right]-2 \xi_{p 5} \frac{\omega_{p 5}}{\omega_{d}} \lambda_{p 5} \dot{\psi}_{p 5}(\tau)+2 \xi_{p 4} \frac{\omega_{p 4}}{\omega_{d}} \lambda_{p 4} \dot{\psi}_{p 4}(\tau)-\lambda_{p 5} \frac{\omega_{p 5}^{2}}{\omega_{d}^{2}} \psi_{p 5}(\tau)+\lambda_{p 4} \frac{\omega_{p 4}^{2}}{\omega_{d}^{2}} \psi_{p 4}(\tau)=-\lambda_{p 4} \ell(\tau) \\
& \lambda_{p 3}\left[\ddot{\psi}_{p 3}(\tau)+\ddot{\psi}_{p 2}(\tau)+\ddot{\psi}_{p 1}(\tau)\right]-2 \xi_{p 4} \frac{\omega_{p 4}}{\omega_{d}} \lambda_{p 4} \dot{\psi}_{p 4}(\tau)+2 \xi_{p 3} \frac{\omega_{p 3}}{\omega_{d}} \lambda_{p 3} \dot{\psi}_{p 3}(\tau)-\lambda_{p 4} \frac{\omega_{p 4}^{2}}{\omega_{d}^{2}} \psi_{p 4}(\tau)+\lambda_{p 3} \frac{\omega_{p 3}^{2}}{\omega_{d}^{2}} \psi_{p 3}(\tau)=-\lambda_{p 3} \ell(\tau) \\
& \lambda_{p 2}\left[\ddot{\psi}_{p 2}(\tau)+\ddot{\psi}_{p 1}(\tau)\right]-2 \xi_{p 3} \frac{\omega_{p 3}}{\omega_{d}} \lambda_{p 3} \dot{\psi}_{p 3}(\tau)+2 \xi_{p 2} \frac{\omega_{p 2} 2}{\omega_{d}} \lambda_{p 2} \dot{\psi}_{p 2}(\tau)-\lambda_{p 3} \frac{\omega_{p 3}^{2}}{\omega_{d}^{2}} \psi_{p 3}(\tau)+\lambda_{p 2} \frac{\omega_{p 2}^{2}}{\omega_{d}^{2}} \psi_{p 2}(\tau)=-\lambda_{p 2} \ell(\tau) \\
& \lambda_{p 1} \ddot{\psi}_{p 1}(\tau)-2 \xi_{p 2} \frac{\omega_{p 2}}{\omega_{d}} \lambda_{p 2} \dot{\psi}_{p 2}(\tau)+2 \xi_{p 1} \frac{\omega_{p 1}}{\omega_{d}} \lambda_{p 1} \dot{\psi}_{p 1}(\tau)-\lambda_{p 2} \frac{\omega_{p 2}^{2}}{\omega_{d}^{2}} \psi_{p 2}(\tau)+\lambda_{p 1} \frac{\omega_{p 1}^{2}}{\omega_{d}^{2}} \psi_{p 1}(\tau)=-\lambda_{p 1} \ell(\tau)
\end{aligned}
$$

The non-dimensional parameters $\psi_{u_{d}}=\frac{u_{d, \text { peak }} \omega_{d}^{2}}{a_{0}}$ and $\psi_{u_{p}}=\frac{u_{p_{\text {peak }}} \omega_{d}^{2}}{a_{0}}=\frac{\left(\sum_{i=1}^{5} u_{p_{i}}\right)_{\text {peak }} \omega_{d}^{2}}{a_{0}}$ describe the peak dynamic response of the deck and of pier, respectively. Moreover, from Eq.(5), it is possible to observe that the five non-dimensional $\Pi$ terms [20]-[21],[35]-[36] that control the system non-dimensional response are:

$$
\Pi_{\omega i}=\frac{\omega_{p i}}{\omega_{d}}, \Pi_{\lambda p i}=\lambda_{p i}=\frac{m_{p i}}{m_{d}}, \Pi_{\xi_{d}}=\xi_{d}, \Pi_{\xi_{p i}}=\xi_{p i} \text { with } i=1, \ldots, 5
$$

in particular, $\Pi_{\omega i}$ represents the $i$-th frequency ratio, $\Pi_{\lambda p i}$ is the $i$-th mass ratio as previously defined, $\Pi_{\xi_{p i}}$ and $\Pi_{\xi_{d}}$ are the inherent viscous damping related to the $i$-th dof of the pier and to the isolator/deck, respectively. Regarding the control parameters of the pier, indeed, the parameters $\omega_{p i}$ are related to the fundamental vibration pulsation $\omega_{p}$ (the first vibration mode) 
as well as the sum of the mass ratios is related to the overall mass ratio $\Pi_{\lambda}=\lambda_{p}=\sum_{i=1}^{5} m_{p i} / m_{d}$ and, finally, all the damping factors are assumed equal to $\Pi_{\xi_{p}}=\xi_{p}$.

The normalized friction coefficients for the FPS devices on the pier and on the abutment are the derived, respectively:

$$
\Pi_{\mu p}\left(\dot{\psi}_{d}\right)=\frac{\mu_{p}\left(\dot{\psi}_{d}\right) g}{a_{0}}, \quad \Pi_{\mu a}\left(\dot{\psi}_{d}+\sum_{i=1}^{5} \dot{\psi}_{p i}\right)=\frac{\mu_{a}\left(\dot{\psi}_{d}+\sum_{i=1}^{5} \dot{\psi}_{p i}\right) g}{a_{0}}
$$

and since these parameters depend on the response through the corresponding velocities, each one is used in its stead as follows [20]:

$$
\Pi_{\mu p}^{*}=\frac{\mu_{p, \max } g}{a_{0}}, \quad \Pi_{\mu a}{ }^{*}=\frac{\mu_{a, \max } g}{a_{0}}
$$

It is worth underlining that even if the two FPS devices are equal, $\Pi_{\mu p}{ }^{*}=\Pi_{\mu a}{ }^{*}$, during the dynamic response the terms of Eq.(8) depend on different velocities.

On the other hand, in the case of a single-column bent viaduct (or neglecting the presence of the abutment) [22],[37], the same 6-degree-of-freedom (dof) model presented above, having 5 degrees of freedom for the elastic RC pier and 1 degree of freedom for the rigid RC deck mass equipped with FPS devices is adopted and shown in Figure 1(a).

The main difference in the form of the equation of motion when the abutment is neglected consists in the absence of the term related to the isolator force placed on the abutment and at the beginning of the paragraph indicated as $F_{a}(t)$.

Note that cracking phenomena [38]-[42] of the RC deck are herein neglected.

\section{GROUND MOTIONS AND INTENSITY MEASURE}

\subsection{Seismic records}

In this study, the record-to-record variability is considered using 30 seismic records selected from 19 seismic different events [43]-[45]. Table 1 reports the details of the earthquakes

\begin{tabular}{|c|c|c|c|c|c|c|c|c|}
\hline \# & Year & Earthquake Name & $\begin{array}{l}\text { Recording } \\
\text { Name }\end{array}$ & $\begin{array}{l}\mathrm{Vs}_{30} \\
{[\mathrm{~m} / \mathrm{sec}]}\end{array}$ & $\begin{array}{l}\text { Source } \\
\text { (Fault Type) }\end{array}$ & $\begin{array}{l}\mathbf{M} \\
{[-]}\end{array}$ & $\begin{array}{l}\text { R } \\
{[\mathrm{km}]}\end{array}$ & $\begin{array}{l}\text { PGA max }_{\text {max }} \\
\text { [g] }\end{array}$ \\
\hline 1 & 1994 & Northridge & Beverly Hills - Mulhol & 356 & Thrust & 6.7 & 13.3 & 0.52 \\
\hline 2 & 1994 & Northridge & Canyon Country-WLC & 309 & Thrust & 6.7 & 26.5 & 0.48 \\
\hline 3 & 1994 & Northridge & LA - Hollywood Stor & 316 & Thrust & 6.7 & 22.9 & 0.36 \\
\hline 4 & 1999 & Duzce, Turkey & Bolu & 326 & Strike-slip & 7.1 & 41.3 & 0.82 \\
\hline 5 & 1999 & Hector Mine & Hector & 685 & Strike-slip & 7.1 & 26.5 & 0.34 \\
\hline 6 & 1979 & Imperial Valley & Delta & 275 & Strike-slip & 6.5 & 33.7 & 0.35 \\
\hline 7 & 1979 & Imperial Valley & El Centro Array \#11 & 196 & Strike-slip & 6.5 & 29.4 & 0.38 \\
\hline 8 & 1995 & Kobe, Japan & Nishi-Akashi & 609 & Strike-slip & 6.9 & 8.7 & 0.51 \\
\hline 9 & 1995 & Kobe, Japan & Shin-Osaka & 256 & Strike-slip & 6.9 & 46 & 0.24 \\
\hline 10 & 1999 & Kocaeli, Turkey & Duzce & 276 & Strike-slip & 7.5 & 98.2 & 0.36 \\
\hline 11 & 1999 & Kocaeli, Turkey & Arcelik & 523 & Strike-slip & 7.5 & 53.7 & 0.22 \\
\hline 12 & 1992 & Landers & Yermo Fire Station & 354 & Strike-slip & 7.3 & 86 & 0.24 \\
\hline 13 & 1992 & Landers & Coolwater & 271 & Strike-slip & 7.3 & 82.1 & 0.42 \\
\hline
\end{tabular}
used for the study. 
P. Castaldo, and G. Amendola

\begin{tabular}{|c|c|c|c|c|c|c|c|c|}
\hline 14 & 1989 & Loma Prieta & Capitola & 289 & Strike-slip & 6.9 & 9.8 & 0.53 \\
\hline 15 & 1989 & Loma Prieta & Gilroy Array \#3 & 350 & Strike-slip & 6.9 & 31.4 & 0.56 \\
\hline 16 & 1990 & Manjil, Iran & Abbar & 724 & Strike-slip & 7.4 & 40.4 & 0.51 \\
\hline 17 & 1987 & Superstition Hills & El Centro Imp. Co. & 192 & Strike-slip & 6.5 & 35.8 & 0.36 \\
\hline 18 & 1987 & Superstition Hills & Poe Road (temp) & 208 & Strike-slip & 6.5 & 11.2 & 0.45 \\
\hline 19 & 1987 & Superstition Hills & Westmorland Fire Stat. & 194 & Strike-slip & 6.5 & 15.1 & 0.21 \\
\hline 20 & 1992 & Cape Mendocino & Rio Dell Overpass & 312 & Thrust & 7.0 & 22.7 & 0.55 \\
\hline 21 & 1999 & Chi-Chi, Taiwan & CHY101 & 259 & Thrust & 7.6 & 32 & 0.44 \\
\hline 22 & 1999 & Chi-Chi, Taiwan & TCU045 & 705 & Thrust & 7.6 & 77.5 & 0.51 \\
\hline 23 & 1971 & San Fernando & LA - Hollywood Stor & 316 & Thrust & 6.6 & 39.5 & 0.21 \\
\hline 24 & 1976 & Friuli, Italy & Tolmezzo & 425 & Thrust & 6.5 & 20.2 & 0.35 \\
\hline 25 & 1980 & Irpinia & Bisaccia & 496 & & 6.9 & 21.3 & 0.94 \\
\hline 26 & 1979 & Montenegro & ST64 & 1083 & Thrust & 6.9 & 21.0 & 0.18 \\
\hline 27 & 1997 & Umbria Marche & ST238 & $\mathrm{n} / \mathrm{a}$ & Normal & 6.0 & 21.5 & 0.19 \\
\hline 28 & 2000 & South Iceland & ST2487 & $\mathrm{n} / \mathrm{a}$ & Strike-slip & 6.5 & 13 & 0.16 \\
\hline 29 & 2000 & South Iceland (a.s.) & ST2557 & $\mathrm{n} / \mathrm{a}$ & Strike-slip & 6.5 & 15.0 & 0.13 \\
\hline 30 & 2003 & Bingol & ST539 & 806 & Strike-slip & 6.3 & 14.0 & 0.30 \\
\hline
\end{tabular}

Table 1: Seismic records used and them characteristics.

\subsection{Intensity measure}

The intensity scale factor, $a_{0}$, of Eq. (5) is the seismic intensity measure (IM) used in this study coherently with the performance-based earthquake engineering (PBEE) [46],[47]. In this study, the abovementioned term coincides with to the spectral pseudo-acceleration, $S_{A}\left(T_{d}, \xi_{d}\right)$, corresponding to the isolated period of the bridge $T_{d}=2 \pi / \omega_{d}$ with the damping ratio $\Pi_{\xi_{d}}=\xi_{d}$. As also observed in [20]-[22], since the spectral acceleration is related to the spectral displacement $S_{A}\left(T_{b}, \xi_{d}\right)=\omega_{d}^{2} S_{d}\left(T_{d}, \xi_{d}\right)$, if all the records are normalized with respect to $S_{A}\left(T_{d}, \xi_{d}\right)$, the normalized displacement and force of the isolated bridge deck, in the hypothesis of both a rigid substructure (pier) and absence of the sliding friction, are equal to 1 for each record without any record-to-record variability. In the following analysis, the damping ratio $\xi_{d}$ is set equal to zero [20],[34],[48] and the corresponding $I M$ is hereinafter denoted to as $I M=a_{0}=S_{A}\left(T_{d}\right)$.

\section{PARAMETRIC STUDY}

In the analysis carried out in this study, the effects of higher order modes due to the flexibility of the elastic RC pier together with of the pier-abutment-deck interaction are investigated and the seismic performance of isolated bridges is assessed. This section describes the results of the parametric study carried out on the two systems of Figure 1 to evaluate the performance of bridge isolated with FPS bearings for different structural properties. The first subsection deals with the response parameters relevant to the seismic performance and the second subsection illustrates the parametric study results.

\subsection{Non-dimensional response parameters examined}

The following response parameters relevant to the seismic performance assessment of isolated bridges are considered: the peak deck displacement relative to the pier for the model of Figure 1(a) as well as the peak deck displacement relative to the pier or to the abutment for the model of Figure 1(b), $u_{d, p e a k}$, either important for the design of the FPS isolator and of 
the seismic joint deck-abutment, the peak pier displacement $u_{p, p e a k}=\left(\sum_{i=1}^{5} u_{p_{i}}\right)_{p e a k}$ (related to the internal forces in the bridge substructure) for the both models. All these relevant response parameters can be defined in non-dimensional form, in line with Eq.s (4) and (6), as follows:

$$
\psi_{u_{d}}=\frac{u_{d s_{\text {paak }}} \omega_{d}^{2}}{a_{0}}, \quad \psi_{u_{p}}=\frac{u_{p_{, \text {peak }}} \omega_{d}^{2}}{a_{0}}=\frac{\left(\sum_{i=1}^{5} u_{p_{i}}\right)_{p e a k} \omega_{d}^{2}}{a_{0}}
$$

Eq.s (4) and (6) are repeatedly and numerically solved in Matlab-Simulink [49] computing a set of samples for each response parameter for the two structural models. As also described in [20],[21],[48],[50], the response parameters are modeled in probabilistic terms [51]-[58]: the generic response parameter $D$ (i.e., the extreme values $\psi_{u_{d}}, \psi_{u_{p}}$ of Eq. (10)) can be fitted by a lognormal distribution estimating the sample geometric mean, $G M(D)$, and dispersion, $\beta(D)$, defined, respectively:

$$
\begin{gathered}
G M(D)=\sqrt[N]{d_{1} \cdot \ldots \cdot d_{N}} \\
\beta(D)=\sigma_{\ln }(D)=\sqrt{\frac{\left(\ln d_{1}-\ln [G M(D)]\right)^{2}+\ldots . .+\left(\ln d_{N}-\ln [G M(D)]\right)^{2}}{N-1}}
\end{gathered}
$$

in which $d_{h}$ is the $h$-th sample realization of $D$, and $N$ represents the total number of samples (i.e., ground motions): $h=1, \ldots, N$. The $k$ th percentile of the response parameter $D$ can be evaluated as:

$$
d_{k}=G M(D) \exp [f(k) \beta(D)]
$$

where $f(k)$ is a function that assumes the following values $f(50)=0, f(84)=1$ and $f(16)=-1[59]$, for the $50^{\text {th }}, 16^{\text {th }}$ and $84^{\text {th }}$ percentile, respectively.

\subsection{Non-dimensional results}

In this section, the results of the parametric study for the two structural configurations developed on the equivalent 6 dof systems, for the different structural properties and 30 ground motion records, are illustrated and commented. Specifically, in line with [2],[11],[13],[25],[60], the parameters $\Pi_{\xi_{d}}=\xi_{d}$ and $\Pi_{\xi_{p}}=\xi_{p}$ are assumed respectively equal to $0 \%$ and $5 \%$, the isolation period $T_{d}$ varies in the range between $2 \mathrm{~s}, 2.5 \mathrm{~s}, 3 \mathrm{~s}, 3.5 \mathrm{~s}$ and $4 \mathrm{~s}$, the elastic RC pier period $T_{p}$ equal to $0.2 \mathrm{~s}, \Pi_{\lambda}=\lambda$ between $0.1,0.15$ and $0.2, \Pi_{\mu}{ }^{*}$ between 0 and 2. The latter one is related to the FPS device on the pier for the model without the abutment and to the FPS isolators, assumed equal, on the pier and on the abutment for the model of Figure 1(b): $\Pi_{\mu p}{ }^{*}=\Pi_{\mu a}{ }^{*}=\Pi_{\mu}{ }^{*}$. For each parameter combination and for the two structural configurations, the differential motion equations (Eq.s (6) and (12)) have been repeatedly and numerically solved adopting the Bogacki-Shampine and Runge-Kutta-Fehlberg integration algorithm available in Matlab-Simulink [49]. After that, for each normalized response parameter, the geometric mean, $G M$, and the dispersion, $\beta$, have been evaluated by means of Eq.s (11) and (12) and are illustrated in Figures 2-3 for the both structural models. Each figure con- 
tains different meshes as many as the values of $\Pi_{\lambda}$ : the arrow indicates the increasing values of $\Pi_{\lambda}$. Note that for the configuration with the pier-abutment-deck interaction (i.e., multispan continuous deck bridge), the peak normalized deck displacement, showed in Figures 2, has always been the one between the deck and the abutment. This is because of the elastic response of the pier that reduces the relative displacement between the deck and itself.

a)

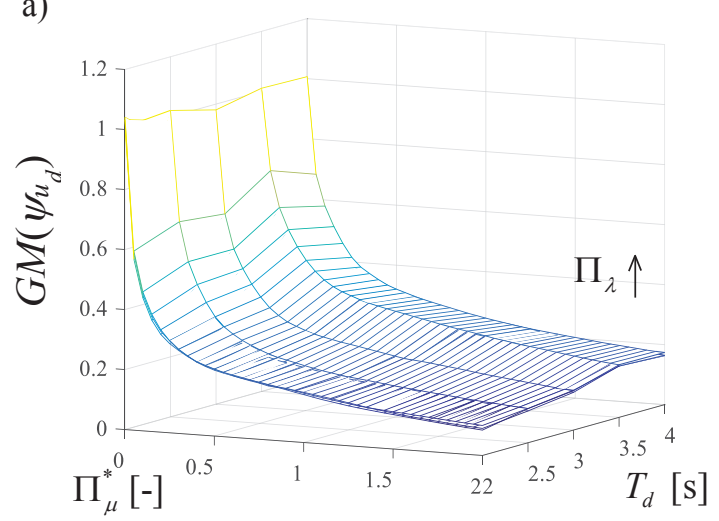

b)

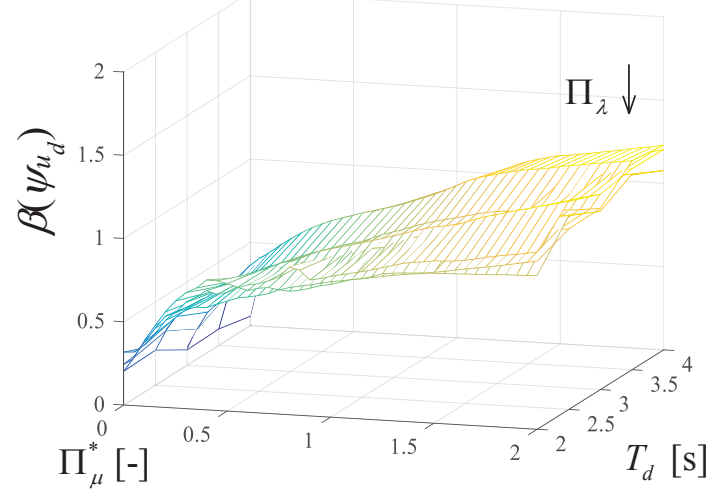

c)

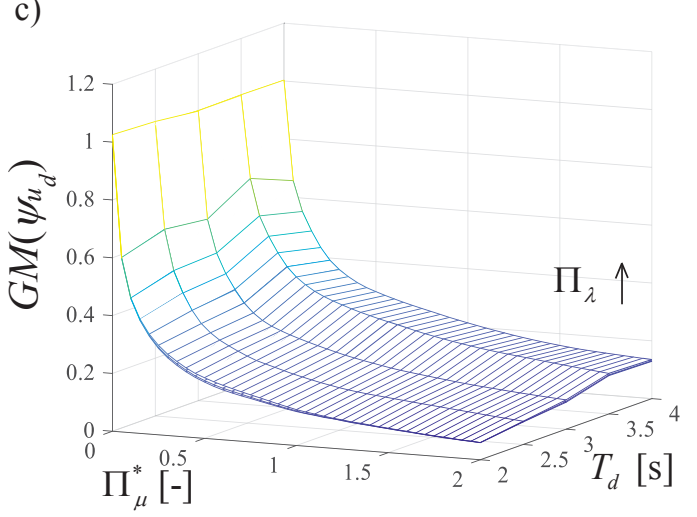

d)

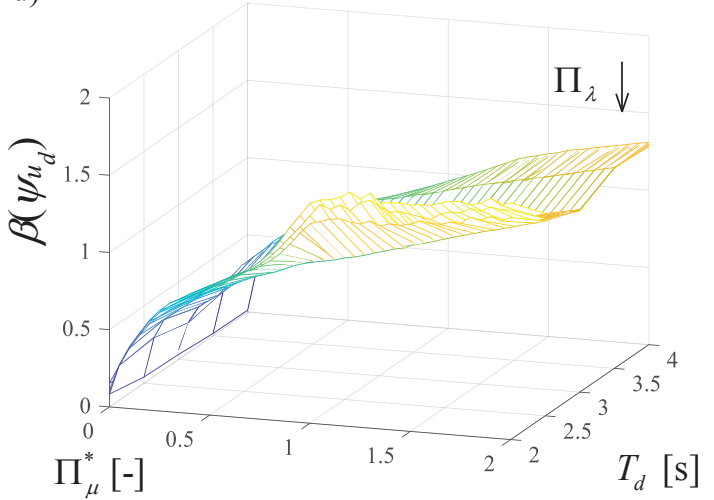

Figure 2: Normalized deck displacement vs. $\Pi^{*}{ }_{\mu}$ and $T_{d}$ : median value ((a): analysis with only pier; (c): analysis with the pier-abutment-deck interaction) and dispersion ((b): analysis with only pier; (d): analysis with the pierabutment-deck interaction) for $T_{p}=0.2 \mathrm{~s}$ and for different values of $\Pi_{\lambda}$.

In Figures 2, GM $\left(\psi_{u_{d}}\right)$ is quite equal to unit for $\Pi_{\mu}^{*}=0$. For $\Pi_{\mu}^{*} \neq 0, G M\left(\psi_{u_{d}}\right)$ increases slightly for increasing $T_{d}$ because of the period elongation. Obviously, $G M\left(\psi_{u_{d}}\right)$ decreases significantly as $\Pi_{\mu}^{*}$ increases showing an hyperbolic trend while it is not heavily influenced by $\Pi_{\lambda}$. The dispersion $\beta\left(\psi_{u_{d}}\right)$, for high $T_{d}$, increases for increasing values of $\Pi_{\mu}^{*}$, as a result of the reduction of the efficiency of the IM. Obviously, in the situation corresponding to $\Pi_{\mu}^{*}=0$, the dispersion is quite zero for all the values of $T_{d}$ and of $\Pi_{\lambda}$ considered. The mass ratio $\Pi_{\lambda}$ does not affect significantly the response dispersion. Despite the trends of the both statistics are similar for the two configurations, it is possible to observe that the values of $G M\left(\psi_{u_{d}}\right)$ are larger in the case of the model without the pier-abutment-deck interaction. On the other hand, higher values of $\beta\left(\psi_{u_{d}}\right)$ are achieved for the model with the pier-abutmentdeck interaction. 
a)

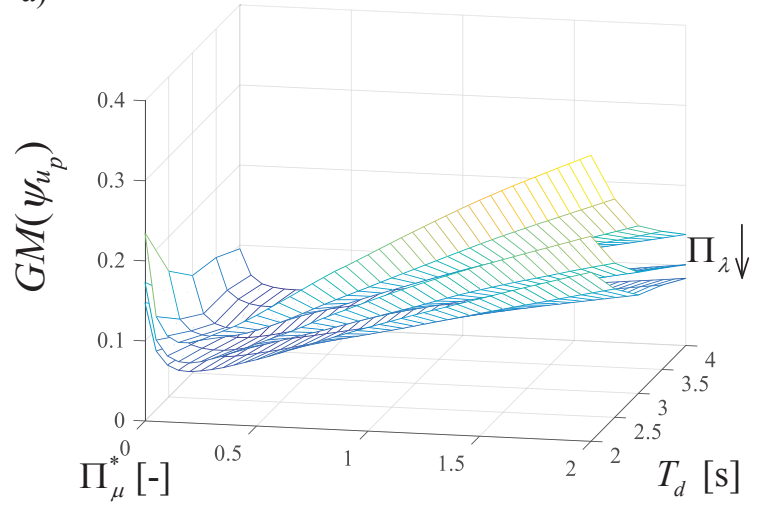

b)

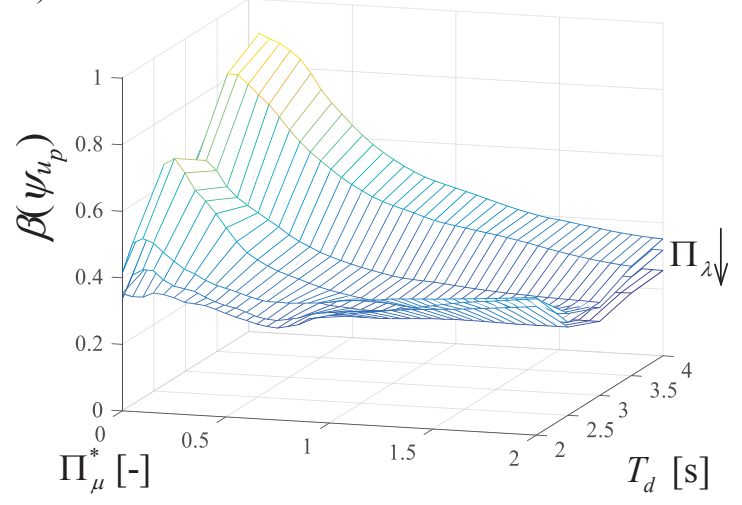

c)

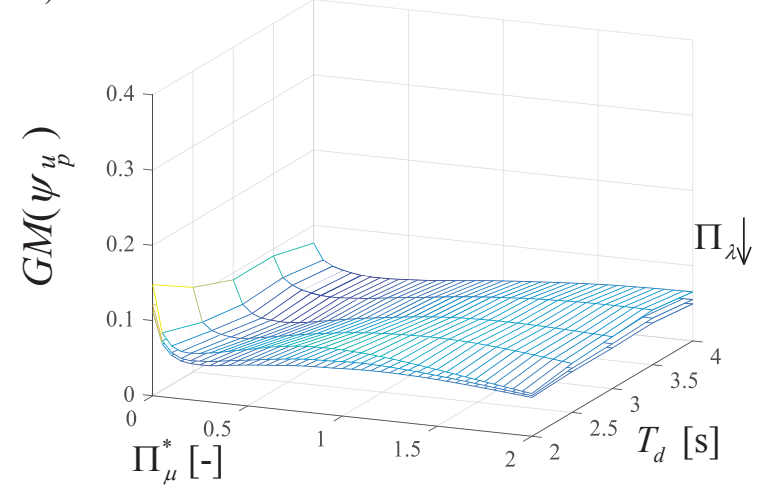

d)

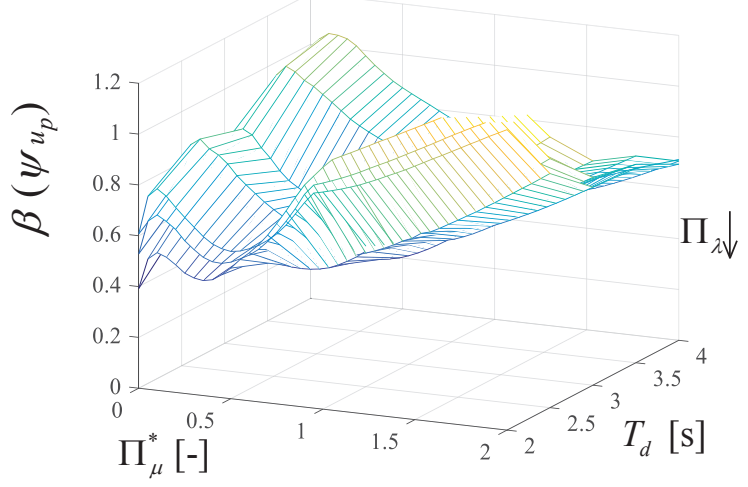

Figure 3: Normalized pier displacement vs. $\Pi^{*} \mu$ and $T_{d}$ : median value ((a): analysis with only pier; (c): analysis with the pier-abutment-deck interaction) and dispersion ((b): analysis with only pier; (d): analysis with the pierabutment-deck interaction) for $T_{p}=0.2 \mathrm{~s}$ and for different values of $\Pi_{\lambda}$.

Figure 3 represents the response statistics of the normalized pier displacement $\psi_{u_{p}}$. For the both structural configurations, $G M\left(\psi_{u_{p}}\right)$ decreases for higher values of $T_{d}$ and of $\Pi_{\lambda}$ as well as for decreasing values of $T_{p}$; whereas it first decreases and then increases for increasing values of $\Pi_{\mu}^{*}$, meaning that there is an optimal value of $\Pi_{\mu}^{*}$ able to minimize the geometric mean of the pier displacement. This optimal value varies in a range that depends on the values of $T_{d}$ and $\Pi_{\lambda}$ and on the structural configuration. Note also that for not optimal values of $\Pi_{\mu}^{*}, G M\left(\psi_{u_{p}}\right)$ is not so high. Conversely, $G M\left(\psi_{u_{p}}\right)$ presents higher values for the structural configuration without the pier-abutment-deck interaction (i.e., single-column bent viaduct). The values of the dispersion $\beta\left(\psi_{u_{p}}\right)$ are very low for low $\Pi_{\mu}^{*}$ values due to the high efficiency of the $I M$ used in this work, and reach their peak for values of $\Pi_{\mu}^{*}$ close to the optimal ones. The other system parameters have a reduced influence on $\beta\left(\psi_{u_{p}}\right)$ compared to the influence of $\Pi_{\mu}^{*}$. Higher values are achieved for the structural configuration with the pierabutment-deck interaction (i.e., multi-span continuous deck bridge). 


\section{OPTIMAL VALUES OF THE SLIDING FRICTION COEFFICIENTS}

Once the results from the analysis are obtained, for each parameter combination (i.e., $\Pi_{\lambda}$ and $T_{d}$ ) and structural model (i.e., single-column bent viaduct and multi-span continuous deck bridge), the optimal values of the normalized sliding friction coefficient, $\Pi^{*}{ }_{\mu \text { opt }}$, that minimize the median $\left(50^{\text {th }}\right.$ percentile $)$ of the normalized pier displacements $\psi_{u_{p}}$ have been assessed and are reported in Figure 4 . Figure 4 reports the variation of $\Pi_{\mu \text {,opt }}^{*}$ with $\Pi_{\lambda}$ and $T_{d}$ and in relation to the two structural models (Figure $4 \mathrm{a}, \mathrm{b}$ ). The optimal values of the sliding friction coefficient manifest a slightly increase as $T_{d}$ decreases, and this is valid for the either the configurations. It is also observed that, especially for high $T_{d}$ values, $\Pi^{*}{ }_{\mu \text {,opt }}$ increases by increasing $\Pi_{\lambda}$ in order to dissipate more energy.
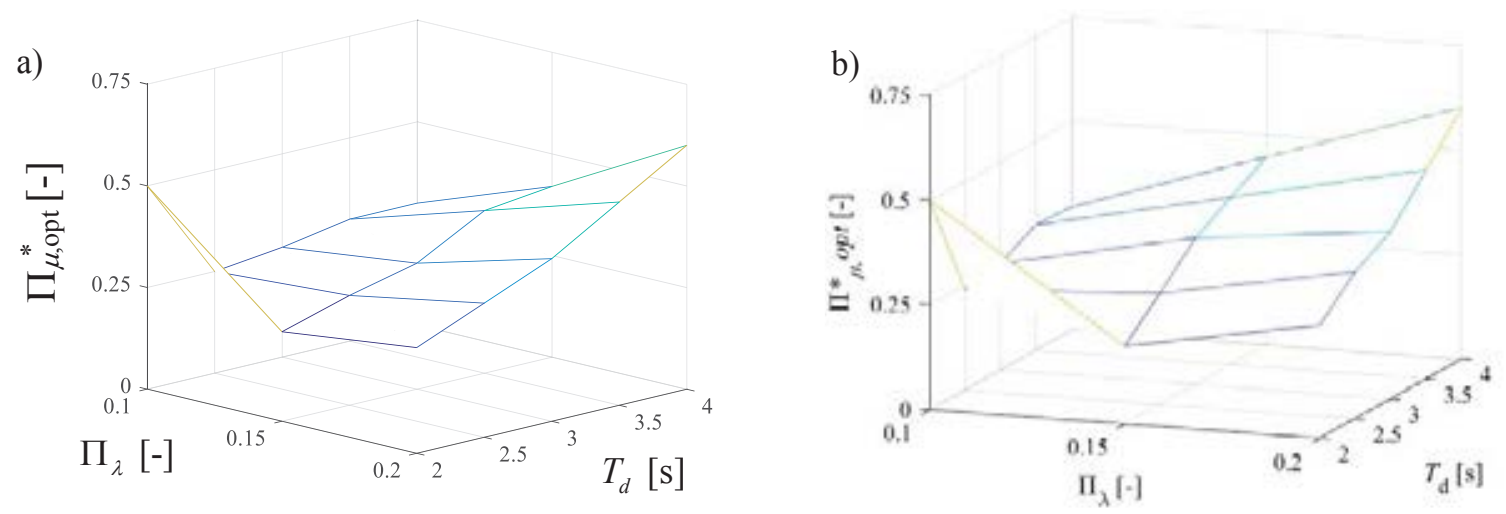

Figure 4: Optimal values of normalized friction that minimize the $50^{\text {th }}$ percentile of the normalized pier displacements vs. $\Pi_{\lambda}$ and $T_{d}$, for $T_{p}=0.2 \mathrm{~s}$; (a) with only pier; (b) with the pier-abutment-deck interaction.

\section{CONCLUSIONS}

This paper summarizes the seismic performance of bridges and viaducts isolated with single concave friction pendulum system bearings focusing on the influence of the pierabutment-deck interaction on the seismic response. The analysis carried out aim to define the optimal isolator friction properties taking into account the uncertainty in the seismic input. Adopting the nondimensionalization of the motion equations, a wide parametric analysis considering several structural properties has been conducted by monitoring the response parameters of interest regarding both an isolated bridge where only the pier response is considered and an isolated bridge where the interaction between pier and abutment is taken into account (i.e., single-column bent viaduct and multi-span continuous deck bridge, respectively). The seismic response of these systems is modelled by employing a six-degree-of-freedom system mainly to capture the effects due to the higher modes of the elastic pier.

As far as the deck response is concerned, the geometric mean of the normalized deck displacement tends to slightly increase for increasing isolation period because of the period elongation and it decreases significantly as the normalized friction increases. It presents higher values in the case of the model with only pier (i.e., single-column bent viaduct). The dispersion increases for increasing both isolation period and normalised friction coefficient. It presents higher values in the case of the model with the pier-abutment-deck interaction.

With regards to the pier response, the geometric mean of the normalized displacement decreases for increasing values of isolation period and of mass ratio, whereas it first decreases 
and then increases for increasing values of normalized friction. Assuming that, an optimal value of normalized friction coefficient such that the pier displacement is minimized does exist. Regarding the dispersion, higher values are observed for the pier-abutment-deck interaction model.

Finally, the optimal values of the normalized friction coefficient, able to minimize the $50^{\text {th }}$ percentile of the pier response, as a function of the structural properties and for the both structural models, are estimated. Higher optimum friction coefficients are required, when the pierabutment-deck interaction (i.e., multi-span continuous deck bridge) is taken into account.

\section{REFERENCES}

[1] M. C. Constantinou, A. Kartoum, A. M. Reinhorn, P. Bradford, Sliding isolation system for bridges: Experimental study, Earthquake Spectra 1992; 8(3): 321-344.

[2] A. Kartoum, M. C. Constantinou, A. M. Reinhorn, Sliding isolation system for bridges: Analytical study, J. Struct. Eng. 1992; 8(3): 345-372.

[3] P. Tsopelas, M. C. Constantinou, Y. S. Kim, S. Okamoto, Experimental study of FPS system in bridge seismic isolation, Earthquake Eng. Struct. Dyn. 1996a; 25(1): 65-78.

[4] A. Ghobarah, H. M. Ali, Seismic performance of highway bridges, Eng. Struct. 1988; 10(3): 157-166

[5] M. Dicleli, S. Buddaram, Effect of isolator and ground motion characteristics on the performance of seismic-isolated bridges. Earth. Engin. and Struc. Dyn. 2006;35(2):233250 .

[6] P. Tsopelas, M. C. Constantinou, S. Okamoto, S. Fujii, D. Ozaki, Experimental study of bridge seismic sliding isolation systems. Engineering Structures, Vol. 18, No. 4, pp. 301-310, 1996.

[7] R.S. Jangid, Seismic Response of Isolated Bridges. J. Bridge Eng., 2004, 9(2): 156-166.

[8] Jangid, R. S. (2008). Equivalent linear stochastic seismic response of isolated bridges. Journal of Sound and Vibration, 309(3-5), 805-822.

[9] Troisi R., Alfano G. 2019. Towns as Safety Organizational Fields: An Institutional Framework in Times of Emergency. Sustainability, 11: 7025, 2019, doi:10.3390/su11247025.

[10] Troisi R., Alfano G. 2020. Firms'crimes and land use in Italy. An exploratory data anlysis. New Metropolitan Perspectives, International Symposium - 4th edition, 27-30 May 2020, pp 10.

[11] N.P. Tongaonkar, R.S. Jangid, Seismic response of isolated bridges with soil-structure interaction. Soil Dynamics and Earthquake Engineering 23 (2003) 287-302.

[12] L. Su, G. Ahmadi, IG. Tadjbakhsh, Comparative study of base isolation systems. Journal of Engineering Mechanic 1989; 115(9):1976-92.

[13] Yen-Po Wang, Lap-Loi Chung, Wei-Hsin Liao. Seismic response analysis of bridges isolated with friction pendulum bearings. Earth.Eng.\& Str. Dyn., 1998; 27, 1069-1093.

[14] VA. Zayas, SS. Low, SA. Mahin, A simple pendulum technique for achieving seismic isolation. Earthquake Spectra 1990; 6(2):317-33. 
[15] G. Mosqueda, AS. Whittaker, GL. Fenves, Characterization and modeling of Friction Pendulum bearings subjected to multiple components of excitation. Journal of Structural Engineering 2004; 130(3):433-442.

[16] A. Mokha, MC. Constantinou, AM. Reinhorn, Teflon Bearings in Base Isolation. I: Testing. Journal of Structural Engineering 1990; 116(2):438-454.

[17] MC. Constantinou, A. Mokha, AM. Reinhorn, Teflon Bearings in Base Isolation. II: Modeling. Journal of Structural Engineering 1990; 116(2):455-474.

[18] R. S. Jangid, Computational numerical models for seismic response of structures isolated by sliding systems, Structural Control and Health Monitoring 2005; 12:117-137.

[19] MC. Constantinou, AS. Whittaker, Y. Kalpakidis, DM. Fenz, GP. Warn, Performance of Seismic Isolation Hardware Under Service and Seismic Loading. Technical Report MCEER-07-0012, 2007.

[20] P. Castaldo, E. Tubaldi, Influence of FPS bearing properties on the seismic performance of base-isolated structures. Earthquake Engin. and Structural Dynamics 2015;44(15):2817-2836.

[21] P. Castaldo, M. Ripani, Optimal design of friction pendulum system properties for isolated structures considering different soil conditions, Soil Dynamics and Earthquake Engineering, 2016, 90:74-87, DOI: 10.1016/j.soildyn.2016.08.025.

[22] P. Castaldo, M. Ripani, R. Lo Piore, Influence of soil conditions on the optimal sliding friction coefficient for isolated bridges. Soil Dynamics and Earth. Engineering, 2018, $111 ; 131-148$.

[23] Zhang, J., \& Huo, Y. (2009). Evaluating effectiveness and optimum design of isolation devices for highway bridges using the fragility function method. Eng. Structures, 31(8), $1648-1660$.

[24] Kunde, M. C., \& Jangid, R. S. (2006). Effects of pier and deck flexibility on the seismic response of isolated bridges. Journal of Bridge Engineering, 11(1), 109-121.

[25] M. Eröz, R. DesRoches. Bridge seismic response as a function of the Friction Pendulum System (FPS) modeling assumptions. Engineering Structures, 30 (2008) 3204-3212.

[26] Eröz, M., \& DesRoches, R. (2013). The influence of design parameters on the response of bridges seismically isolated with the friction pendulum system (FPS). Engineering Structures, 56, 585-599.

[27] P. Castaldo, B. Palazzo, P. Della Vecchia, Seismic reliability of base-isolated structures with friction pendulum bearings. Engineering Structures 2015;95:80-93.

[28] P. Castaldo, B. Palazzo, P. Della Vecchia, Life-cycle cost and seismic reliability analysis of 3D systems equipped with FPS for different isolation degrees, Engineering Structures, 2016;125:349-363, http://dx.doi.org/10.1016/j.engstruct.2016.06.056.

[29] Castaldo, P., Palazzo, B., Ferrentino, T., \& Petrone, G. (2017). Influence of the strength reduction factor on the seismic reliability of structures with FPS considering intermediate PGA/PGV ratios. Composites Part B: Engineering, 115, 308-315.

[30] Palazzo, B., Castaldo, P., \& Della Vecchia, P. (2014, September). Seismic reliability analysis of base-isolated structures with friction pendulum system. In 2014 IEEE Work- 
shop on Environmental, Energy, and Structural Monitoring Systems Proceedings (pp. 16). IEEE.

[31] P. Castaldo, G. Amendola, B. Palazzo, Seismic fragility and reliability of structures isolated by friction pendulum devices: Seismic reliability-based design (SRBD), Earthquake Engineering and Structural Dynamics, 2017; 46(3); 425-446, DOI: 10.1002/eqe.2798.

[32] P. Castaldo, B. Palazzo, T. Ferrentino, Seismic reliability-based ductility demand evaluation for inelastic base-isolated structures with friction pendulum devices, Earthquake Engineering and Structural Dynamics, 2016; DOI: 10.1002/eqe.2854.

[33] P. Castaldo, G. Alfano, Seismic reliability-based design of hardening and softening structures isolated by double concave sliding devices, Soil Dynamics and Earth. Eng., 129: 105930, 2020.

[34] P. Castaldo, B. Palazzo, G. Alfano, MF. Palumbo, Seismic reliability-based ductility demand for hardening and softening structures isolated by friction pendulum bearings, 2018, Structural Control and Health Monitoring, e2256. https://doi.org/10.1002/stc.2256.

[35] TL. Karavasilis, CY. Seo, N. Makris, Dimensional Response Analysis of Bilinear Systems Subjected to Non-pulse like Earthquake Ground Motions. J. of Str. Eng. 2011;137(5):600-606.

[36] M. Barbato, E. Tubaldi, A probabilistic performance-based approach for mitigating the seismic pounding risk between adjacent buildings. Earth. Engin. \& Str. Dyn. 2013;42(8):1203-1219.

[37] MJN. Priestley, F. Seible, GM. Calvi, Seismic design and retrofit of bridges. Wiley,1996.

[38] Bertagnoli, G., Mancini, G., Tondolo, F. Early age cracking of massive concrete piers, Magazine of Concrete Research, 2011, 63, 10, 1, 723-736.

[39] Bertagnoli G., Mancini G., Recupero A., Spinella N., Rotating compression field model for reinforced concrete beams under prevalent shear actions, Structural Concrete, 2011, $12,3,178-186$.

[40] Bertagnoli G., Mancini G. Failure analysis of hollow-core slabs tested in shear. Structural Concrete, 2009, 10, 3, 139-152.

[41] Mancini G., Carbone V.I., Bertagnoli G., Gino, D. Reliability-based evaluation of bond strength for tensed lapped joints and anchorages in new and existing reinforced concrete structures, Structural Concrete, 2018, 19, 3, 904-917.

[42] Bertagnoli G., Gino D., Martinelli, E. A simplified method for predicting early-age stresses in slabs of steel-concrete composite beams in partial interaction, Engineering Structures, 2017,140, 286-297.

[43] PEER, Pacific Earthquake Engineering Research Center http://peer.berkeley.edu/

[44] ITACA, Italian Accelerometric Archive http://itaca.mi.ingv.it/ItacaNet/itaca10 links.htm

[45] ISESD, Internet-Site for European Strong-Motion Data http://www.isesd.hi.is/ESD_Local/frameset.htm 
[46] H. Aslani, E. Miranda, Probability-based seismic response analysis. Engineering Structures 2005;27(8):1151-1163.

[47] Porter KA. An overview of PEER's performance-based earthquake engineering methodology. Proceedings, Proceedings of the 9th International Conference on Application of Statistics and Probability in Civil Engineering (ICASP9), San Francisco, California, 2003.

[48] Ryan K, Chopra A. Estimation of Seismic Demands on Isolators Based on Nonlinear Analysis. Journal of Structural Engineering 2004;130(3):392-402.

[49] Math Works Inc. MATLAB-High Performance Numeric Computation and Visualization Software. User's Guide. Natick: MA, USA; 1997.

[50] T. Karavasilis, C. Seo, Seismic structural and non-structural performance evaluation of highly damped self-centering and conventional systems. Eng. Structures 2011,33(8):2248-2258.

[51] Garzillo C., Troisi R. Le decisioni dell'EMA nel campo delle medicine umane. In EMA e le relazioni con le Big Pharma - I profili organizzativi della filiera del farmaco, G. Giappichelli, 85-133, 2015.

[52] De Iuliis, M., \& Castaldo, P. (2012). An energy-based approach to the seismic control of one-way asymmetrical structural systems using semi-active devices. Ingegneria Sismica-International Journal of Earthquake Engineering, 29(4), 31-42.

[53] Golzio L. E., Troisi R. The value of interdisciplinary research: a model of interdisciplinarity between legal re-search and research in organizations. Journal For Development And Leadership, 2: 23-38, 2013.

[54] Basone, F., Castaldo, P., Cavaleri, L., \& Di Trapani, F. (2019). Response spectrum analysis of frame structures: reliability-based comparison between complete quadratic combination and damping-adjusted combination. Bulletin of Earthquake Engineering, 17(5), 2687-2713.

[55] Nese A., Troisi R. Corruption among mayors: evidence from Italian Court of Cassation judgments, Trends In Organized Crime, 1-26, 2018. DOI:10.1007/s12117-018-9349-4.

[56] Troisi R., Golzio, L. E. Legal studies and organization theory: a possible cooperation. Manageable cooperation - European Academy of Management: 16th EURAM Conference, Paris, 1-2, 1-4 June 2016.

[57] Troisi R., Guida V. Is the Appointee Procedure a Real Selection or a Mere Political Exchange? The Case of the Italian Health-Care Chief Executive Officers. Journal of Entrepreneurial and Organizational Diversity, 7 (2): 19-38, 2018, DOI:10.5947/jeod.2018.008.

[58] Troisi R. Le risorse umane nelle BCC: lavoro e motivazioni al lavoro. In Progetto aree bianche. Il sistema del credito cooperativo in Campania, 1: 399-417, 2012.

[59] Ang AHS, Tang WH. Probability Concepts in Engineering-Emphasis on Applications to Civil and Environmental Engineering. John Wiley \& Sons, New York, USA; 2007.

[60] Michael D. Symans, Steven W. Kelly. Fuzzy logic control of bridge structures using intelligent semi-active seismic isolation systems. Earthquake Engng. Struct. Dyn. 28, $37 ð 60$ (1999). 